\title{
Homogeneity Analysis of Precipitation Series in North Iraq
}

\author{
Omar M. A. Mahmood Agha ${ }^{1}$, S. Çağatay Bağçaci², Nermin Şarlak ${ }^{2}$ \\ ${ }^{1}$ (Department of Dams and Water Resources Engineering, Mosul University, Mosul, Iraq) \\ ${ }_{2}^{2}$ (Department of Civil Engineering, Karamanoglu Mehmetbey University, Karaman, Turkey)
}

\begin{abstract}
Reliability and quality of historical precipitation data are subjected to keen evaluation before a study in water resources, hydrological processes, and climate change fields. In this context, homogeneity tests emerge as a useful tool to control the data reliability and quality. In this study, the homogeneity of the annual and seasonal precipitation data throughout the north of Iraq was investigated using the Pettit, Standard Normal Homogeneity (SNH), Buishand (BR), and Von Neumann (VNR) tests at a significance level of 0.05. Long-term precipitation records taken from nine meteorological stations, were analyzed by each of the four homogeneity tests. Based on annual data, the results of the SNHT test indicated the four stations as inhomogeneous. Moreover, Pettit test exhibited inhomogeneous results for Mosul and Derbandghan stations. The spring precipitation data for all stations were classified as useful except for the Dokan station which was classified as doubtful for the spring precipitation data. As a result, it was concluded that 2, 3, and 1 out of 9 stations were assessed as doubtful for annual, winter, and spring precipitation data, respectively.
\end{abstract}

Keywords: Homogeneity, Pettitt, Buishand, SNHT, Von Neumann, Iraq.

\section{Introduction}

Long-term systematic precipitation series constitute great importance in the study of natural variability of climate and hydrology. Nevertheless, the precipitation data may be suffered from non-climatic factors that results in inhomogeneity of historical records. In fact, the non-climatic factors that caused the variations of longterm time records are the location of the stations, instruments; formulae used to calculate the mean, observing practices and the station environment (Peterson et al., 1998). For this reason, the reliability and homogeneity of the data recorded at meteorological stations should be tested before any statistical research.

The homogeneity tests of precipitation time series are classified into two groups as 'absolute method 'and 'relative method'. The first method is applied for each station separately, whereas the second method is dependent on the neighboring stations (Wijngaard et al., 2003). The relative tests can give good results in case of the high correlation between the candidate stations and existing sufficient number of neighboring stations. In this study, absolute tests are performed because of the random distribution of the stations located on different geographical point having dissimilar rainfall patterns.

A considerable amount of paper has been published on testing the homogeneity of precipitation and temperature data series. For example, Tuomenvirta et al., (2000) used the SNHT test for checking the homogeneity of the monthly maximum and minimum temperature data series. Wijngaard et al., (2003) employed the SNHT, BR, Pettitt and VNR tests to detect the reliability and homogeneity of daily precipitation and temperature data series. Yildırım et al., (2004) used a Kruskall Wallis test in their study to test the homogeneity of precipitation data series. Kang and Yusof (2012) applied the BR and Pettitt test for examining the homogeneity of daily rainfall data. Mahmood Agha and Şarlak (2016) used the SNH and Pettit tests to check the homogeneity of precipitation and temperature data series in Iraq region. Kahya, et al., (2016) checked the homogeneity of the monthly precipitation data sets at 160 meteorological stations in Turkey using the SNH, Pettitt and BR tests.

Several studies relevant with Middle East regions have been published to test the reliability and homogeneity of the precipitation data series. Karabork et al., (2007) analyzed the homogeneity of precipitation data of 212 stations in Turkey belonging to 1973-2002, using the SNH and Pettitt tests. They expressed that the 43 out of 212 stations were impacted from non-climatic conditions resulting in inhomogeneity. AL-Lami, et al., (2014) applied the homogeneity tests for examining the reliability of annual rainfall series in Iraq from 1981 to 2010 using the SNHT, the BR, Pettitt, and VNR tests. Their results showed that the 30\% of stations was inhomogeneous at 5\% significance level. Talaee, et al., (2014) tested the homogeneity of annual and monthly rainfall data in Iran belonging to 1966-2005 using the Bayesian, Cumulative Deviations, and VNR tests at 5\% level. They found that the monthly precipitation data series for all stations are homogeneous and considered as "useful", while monthly precipitation data series belonging to 7 out of 41 stations are inhomogeneous according to the VNR test. They emphasized that the VNR test is more sensitive to detecting the inhomogeneity in the precipitation data series than the Bayesian and Cumulative Deviations tests.

This study was performed to detect the homogeneity of annual and seasonal precipitation data series at nine synoptic meteorological stations located in Northern Iraq using four absolute tests as SNH, Pettitt, BR, 
VNR. This study complements previous studies on the subject by testing some stations have not been tested before and analyzing the homogeneity of long-term annual and seasonal data in Iraq.

\section{Data and methodology}

The study site is located in the northern part of Iraq, covering an area $63353 \mathrm{~km}^{2}$ which lies between the latitudes of $35^{\circ}$ and $37^{\circ} 22^{\circ} \mathrm{N}$ and the longitudes of $41^{\circ} 55^{\circ}$ and $46^{\circ} 35^{\circ} \mathrm{E}$ as shown in Figure 1. Historical records of precipitation taken from nine climate stations was provided from the Iraqi Meteorological Organization and Seismology (IMOS). Descriptive statistics of precipitation records of northern Iraq zone is presented in Table 1.

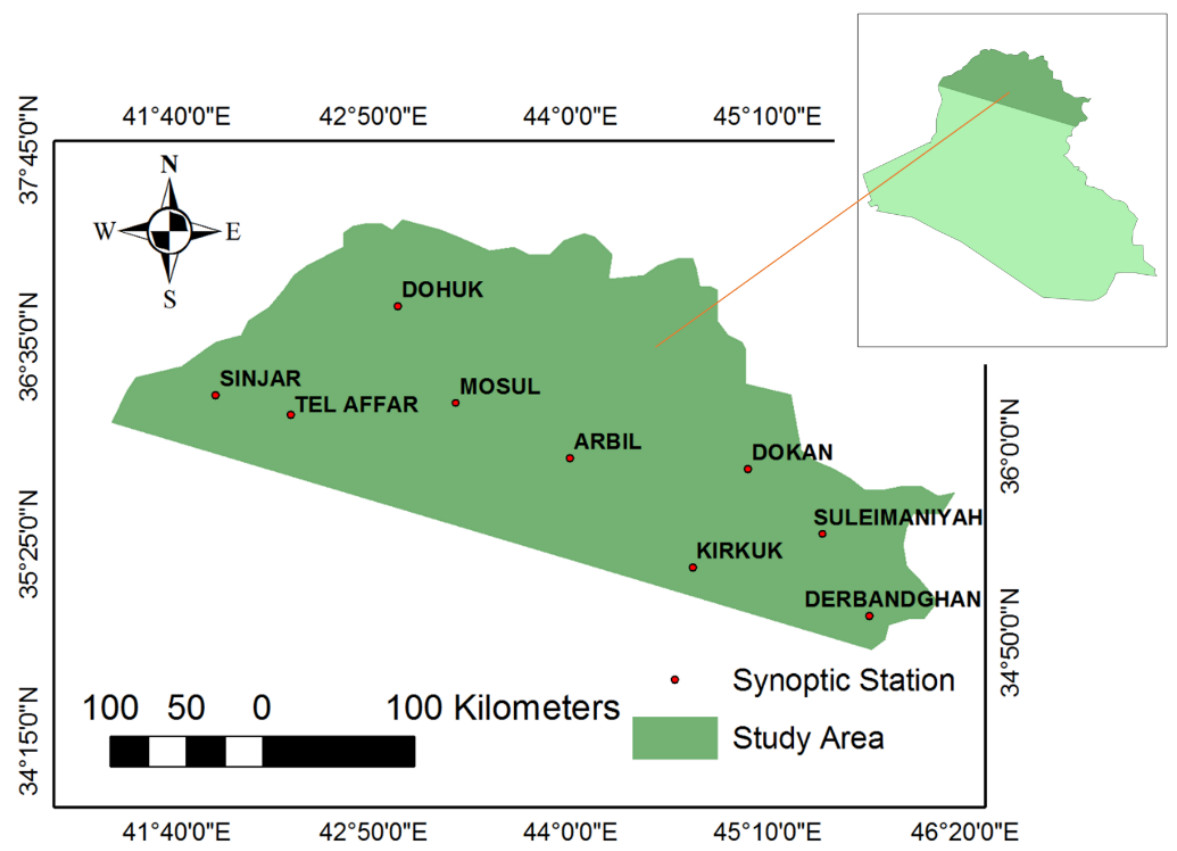

Figure 1. Locations of meteorological stations in northern Iraq

Table 1. Descriptive statistics of stations' precipitation data series

\begin{tabular}{|c|c|c|c|c|c|c|}
\hline STATIONS & $\begin{array}{c}\text { The number of } \\
\text { observed years. }\end{array}$ & The period & Minimum & Maximum & Mean & Std. dev. \\
\hline Mosul & 74 & $1937-2010$ & 193.8 & 633.0 & 378.0 & 109.7 \\
\hline Dohuk & 68 & $1943-2010$ & 225.2 & 911.5 & 569.9 & 170.2 \\
\hline Arbil & 70 & $1941-2010$ & 157.1 & 886.0 & 430.9 & 141.2 \\
\hline Suleimaniyah & 70 & $1941-2010$ & 339.4 & 1243.6 & 700.4 & 192.2 \\
\hline Kirkuk & 71 & $1940-2010$ & 134.9 & 769.9 & 367.0 & 129.2 \\
\hline Telaffer & 70 & $1941-2010$ & 134.2 & 614.4 & 320.6 & 108.0 \\
\hline sinjar & 70 & $1941-2010$ & 164.2 & 669.5 & 378.5 & 137.7 \\
\hline Dokan & 66 & $1945-2010$ & 365.8 & 1468.4 & 766.8 & 226.2 \\
\hline Derbandghan & 49 & $1962-2010$ & 295.7 & 1234.9 & 675.1 & 199.6 \\
\hline
\end{tabular}

\subsection{Homogeneity tests}

Many methods have been proposed to test the homogeneity of the precipitation data. In this study, four homogeneity tests were selected; namely SNHT, BR test, Pettitt test, and VNR test. Under the null hypothesis, the annual and seasonal data are independent and identically random distributed except for VNR test. Under the alternative hypothesis, SNHT, BR and Pettitt tests assume that there is a date at which a change in a mean of data series has occurred. On the contrary, VNR test does not give any information on the break year.

There are some differences capturing the break point among Pettitt, SNHT, and BR. Pettitt and BR tests tend to identify the break point in the middle of the time series, whereas the SNHT detects break point generally at the beginning or end of the time series. 


\section{Pettitt Test}

This test is the non-parametric rank test that can reveal the break point (month or year) at a continuous data (Pettitt, 1979). The null hypothesis of this test is that data are independent and randomly distributed. This means that data follow same distribution. A brief description of the methodology is as follows:

1. The observations $(\mathrm{X})$ are ranked from 1 to $\mathrm{N}$ (i.e. $\mathrm{X}_{1}, \mathrm{X}_{2} \ldots \mathrm{X}_{\mathrm{N}}$ ).

2. The value of $\mathrm{V}_{\mathrm{i}, \mathrm{N}}$ is estimated from:

$\mathrm{V}_{\mathrm{i}}=\mathrm{N}+1-2 \mathrm{R}_{\mathrm{i}} \quad \mathrm{i}=1,2,3, \ldots \ldots \mathrm{N}$

where $R_{i}$ is the rank of $X_{i}$ in the sample of $N$ observations.

3. The value of $U_{i}$ is estimated from:

$$
\begin{aligned}
& \mathrm{U}_{\mathrm{i}}=\mathrm{U}_{\mathrm{i}-1}+\mathrm{V}_{\mathrm{i}} \\
& \mathrm{U}_{1}=\mathrm{V}_{1}
\end{aligned}
$$

4. The value of $\mathrm{K}_{\mathrm{N}}$ is:

$\mathrm{K}_{\mathrm{N}}=\max _{1 \leq \mathrm{i} \leq \mathrm{N}}\left|\mathrm{U}_{\mathrm{i}}\right|$

5. The value of $\mathrm{P}_{\mathrm{OA}}$ is estimated from:

$P_{O A}=2 e^{\left\{-\frac{6 K_{N}^{2}}{\left(N^{3}+N^{2}\right)}\right\}}$

The null hypothesis is rejected when $\mathrm{P}_{\mathrm{OA}}$ is less than $\alpha$, where $\alpha$ is the statistical significance level of the test.

\section{Standard Normal Homogeneity Test (SNHT)}

This method was proposed by Alexandersson (1986). The null hypothesis is same as the Pettitt test. The statistic $\mathrm{T}(\mathrm{k})$ is computed as:

$T(k)=k \bar{z}_{1}^{2}+(n-k) \bar{z}_{2}^{2} \quad \mathrm{k}=1,2, \ldots \ldots . . \mathrm{n}$

$\bar{Z}_{1}=\frac{1}{k} \frac{\sum_{i=1}^{k}\left(Y_{i}-\bar{Y}\right)}{s}$ and $\bar{Z}_{2}=\frac{1}{n-k} \frac{\sum_{i=k+1}^{n}\left(Y_{i}-\bar{Y}\right)}{s}$

If a break point exists on the data series, $\mathrm{T}(\mathrm{k})$ reaches a maximum near the year of $\mathrm{k}=\mathrm{K}$. The test statistic $\mathrm{T}_{\mathrm{o}}$ is calculated as:

$\mathrm{T}_{\mathrm{o}}=\max (\mathrm{T}(\mathrm{k})) \quad$ for $1 \leq \mathrm{k}<\mathrm{n}$

The test statistic, $\mathrm{T}_{\mathrm{c}}$ was calculated based on the test statistic $T(n)$ as follows:

$T_{C}=\frac{n(T(n))^{2}}{n-2+(T(n))^{2}}$

The null hypothesis is rejected when $\mathrm{T}_{\mathrm{o}}$ is greater than the critical value. Alexandersson (1986) gave the critical values for $\mathrm{T}_{\mathrm{o}}$ based on sample size. For example, the critical value is 8.8 for a 70 -year sample size.

\section{Buishand Test}

This test is based on the adjusted partial sums or cumulative deviations from the mean (Buishand, 1982). The null hypothesis is same as the Pettitt test. The adjusted partial sum is calculated as:

$S_{o}^{*}=0 ; S_{k}^{*}=\sum_{i=1}^{k}\left(X_{i}-\bar{X}\right), K=1,2, \ldots \ldots . N$

where $\bar{X}$ is the mean of time series observations $\left(\mathrm{X} 1, \mathrm{X} 2, \ldots \ldots \mathrm{X}_{\mathrm{N}}\right)$ and $\mathrm{K}$ is the number of the observation at which a break point is occurring. Rescaled adjusted partial sums are determined as follows:

$S_{k}^{* *}=\frac{S_{k}^{*}}{D_{X}}, k=1,2, \ldots \ldots \ldots, N$
$D_{X}=\sqrt{\frac{\sum_{i=1}^{N}\left(x_{i}-\bar{x}\right)^{2}}{N}}$

The statistic Q is used for testing homogeneity:

$Q=\max _{0 \leq k \leq N}\left|S_{k}^{* *}\right|$ 
The null hypothesis is accepted, when the value of $Q / \sqrt{N}$ is less than the critical values given by Buishand (1982).

\section{Van Neumann Test}

This test is the widely used for testing the homogeneity, defined as the mean square successive (year to year) difference (Von Neumann, 1941). The null hypothesis is that the data are dependent.

$N=\sum_{i=1}^{n-1}\left(Y_{i}-Y_{i+1}\right)^{2} / \sum_{i=1}^{n}\left(Y_{i}-\bar{Y}\right)^{2}$

If the value of $\mathrm{N}$ is equal to 2 , that mean the sample is homogeneous. while the values of $\mathrm{N}$ less than 2 , the sample has a breakpoint (Buishand, 1981). This test gives no information about the break point. The critical values for $\mathrm{N}$ can be taken from Buishand (1981).

\section{Results and Discussion}

The homogeneity of the annual and seasonal precipitation data was tested for each station in the north of Iraq by using the Pettitt, the SNH, BR, and VNR tests. The results of homogeneity tests were checked at a 5\% significance level. Data series were considered to be inhomogeneous when the p-values were lower than 5\% significance level. The results of the homogeneity tests for the annual precipitation data are presented in Figure 2. According to the results of the Pettitt (SNHT) test, annual precipitation data series belonging to 2 (4) out of 9 stations were found to be inhomogeneous, whereas BR (VNR) tests showed that the annual precipitation data series were homogeneous for all stations except for Darbandikhan (Arbil).
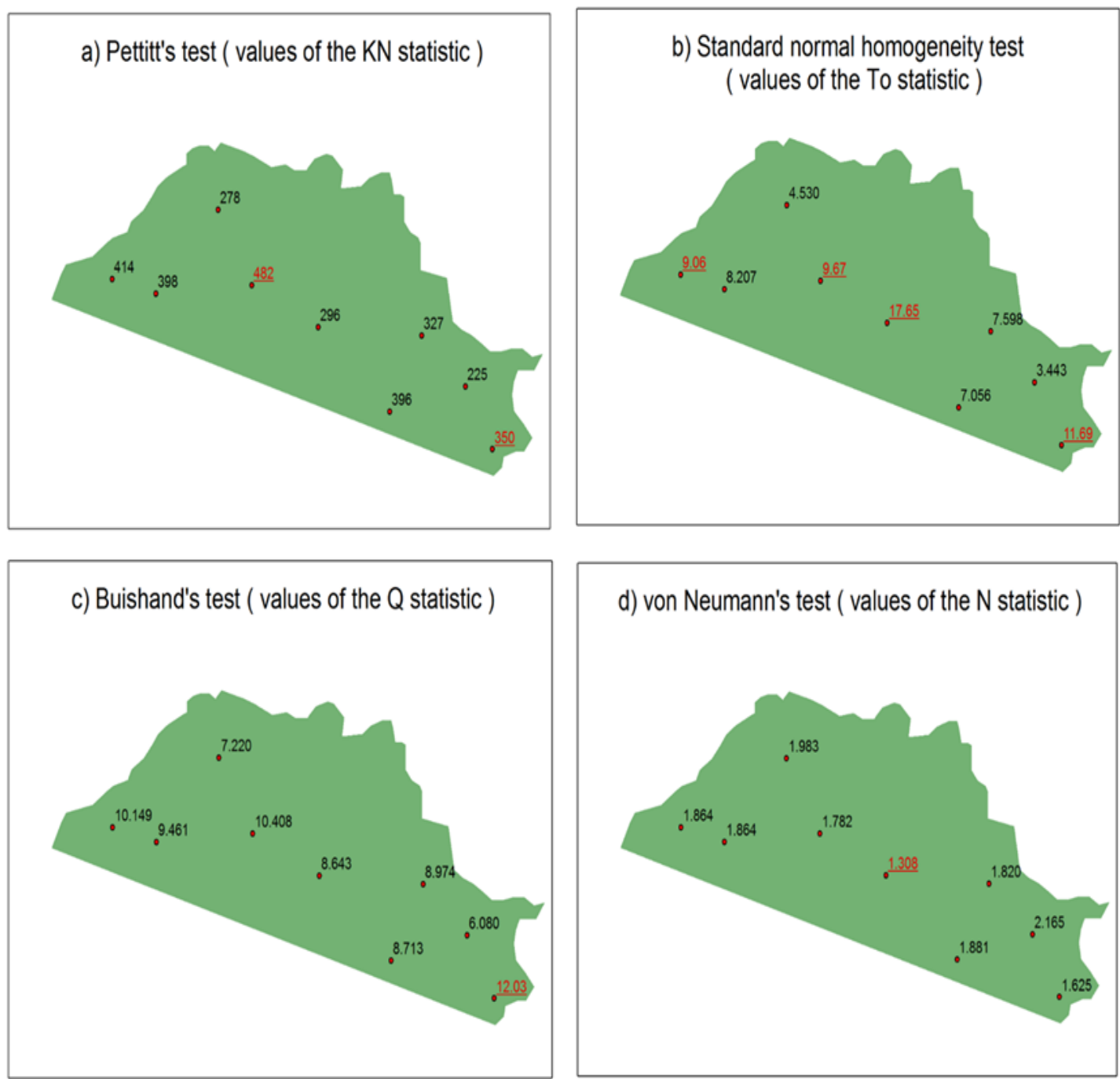

Figure 2. The distribution of homogenous and inhomogeneous stations for the annual precipitation series. (Red color refers to the inhomogeneity stations at the $5 \%$ significance level). 
In fact, the annual precipitation data belonging to Mosul, and Darbandikhan, (Mosul, Arbil, Sinjar, and Darbandikhan) stations showed inhomogeneity characteristic according to Pettitt (SNH) test. In fact, the highest number of the inhomogeneous precipitation data series were obtained from SNHT. All homogeneity tests except for VNR indicated that the break point at the Darbandikhan station was detected in 1988, while the break point at Mosul station was found in 1996 (1997) according to the Pettitt (SNH) test.

Schonwiese and Rapp (1997) classified the precipitation series into: 'useful', 'doubtful' and 'suspect' depending on the number of inhomogeneous results obtained from homogeneity tests. The station is considered as useful; doubtful; and suspect when the 0 or 1; 2; and 3 or 4 tests reject the null hypothesis, respectively. Our results showed that the 6,2 , and 1 out of 9 stations in North of Iraq were classified as useful, doubtful, and suspect for the annual precipitation data.

Regarding seasonal precipitation series, the homogeneity of precipitation time series was also tested for winter (December-February) and spring (March-May) seasons. As shown in Table 2, VNR test detects more inhomogeneous winter precipitation series than the spring. 2 out of 9 stations were found to be inhomogeneous based on the results of the Pettitt and SNH tests. In fact, the winter precipitation data in Mosul and Darbandikhan (Arbil and Dokan) stations were inhomogeneous according to Pettitt (SNH) test. Since the two homogeneity tests detected the winter precipitation series of Arbil, Dokan, and Darbandikhan as inhomogeneous; the series were labeled as doubtful. Consequently, the results of the trend analysis must be taken a serious perspective of the existence of possible inhomogeneities.

Table 2. The test results for the winter precipitation series.

\begin{tabular}{|c|c|c|c|c|c|c|c|c|}
\hline \multirow[t]{2}{*}{ STATIONS } & \multicolumn{2}{|c|}{ Pettitt's test } & \multicolumn{2}{|c|}{ SNHT } & \multicolumn{2}{|c|}{ BR test } & \multicolumn{2}{|c|}{ VNR test } \\
\hline & $\mathrm{K}_{\mathrm{N}}$ & p-value & $\mathrm{T}_{\mathrm{o}}$ & p-value & $\mathrm{Q}$ & p-value & $\mathrm{N}$ & p-value \\
\hline Mosul & $529(1955)^{*}$ & $0.021^{*}$ & 7.188 & 0.132 & 10.128 & 0.085 & 1.741 & 0.129 \\
\hline Dohuk & 348 & 0.149 & 4.066 & 0.456 & 6.505 & 0.462 & 2.120 & 0.702 \\
\hline Arbil & 324 & 0.249 & $29.71(1943)^{*}$ & $0.000^{*}$ & 10.243 & 0.064 & $1.016^{*}$ & $0.000^{*}$ \\
\hline Suleimaniyah & 166 & 0.928 & 3.413 & 0.624 & 4.659 & 0.855 & 2.040 & 0.571 \\
\hline Kirkuk & 236 & 0.646 & 9.060 & 0.068 & 5.890 & 0.606 & $1.609^{*}$ & $0.048^{*}$ \\
\hline Telaffer & 248 & 0.558 & 4.621 & 0.354 & 5.443 & 0.692 & 2.081 & 0.609 \\
\hline Sinjar & 397 & 0.098 & 5.231 & 0.279 & 7.710 & 0.279 & 1.934 & 0.382 \\
\hline Dokan & 304 & 0.231 & $11.08(2006)^{*}$ & $0.012^{*}$ & 8.168 & 0.209 & $1.610^{*}$ & $0.049^{*}$ \\
\hline Derbandghan & $312(1991)^{*}$ & $0.007^{*}$ & 7.928 & 0.060 & $9.7(1991)^{*}$ & $0.026^{*}$ & 1.619 & 0.089 \\
\hline
\end{tabular}

Note: * refers to the inhomogeneous stations at the $5 \%$ significance level.

As for spring precipitation series, 1 and 3 out of nine stations showed inhomogeneity based on the Pettitt and BR test, respectively (can be seen in Table 3). On the other hand, BR test detects only one inhomogeneous series in winter season.

Table 3. The test results for the spring precipitation series.

\begin{tabular}{|c|c|c|c|c|c|c|c|c|}
\hline \multirow[t]{2}{*}{ STATIONS } & \multicolumn{2}{|c|}{ Pettitt's test } & \multicolumn{2}{|c|}{ (SNHT) } & \multicolumn{2}{|c|}{ BR test } & \multicolumn{2}{|c|}{ VNR test } \\
\hline & $\mathrm{K}_{\mathrm{N}}$ & p-value & $\mathrm{T}_{\mathrm{o}}$ & p-value & Q & p-value & $\mathrm{N}$ & p-value \\
\hline Mosul & 449 & 0.076 & 7.240 & 0.150 & 9.205 & 0.146 & 2.103 & 0.666 \\
\hline Dohuk & 348 & 0.155 & 7.020 & 0.118 & 8.875 & 0.148 & 2.288 & 0.886 \\
\hline Arbil & 296 & 0.357 & 6.484 & 0.171 & 9.956 & 0.082 & 2.248 & 0.845 \\
\hline Suleimaniyah & 272 & 0.443 & 6.014 & 0.226 & 8.385 & 0.201 & 2.331 & 0.920 \\
\hline Kirkuk & 332 & 0.247 & 6.179 & 0.231 & 10.546 & 0.057 & 2.362 & 0.950 \\
\hline Telaffer & 394 & 0.098 & 7.487 & 0.121 & 9.424 & 0.116 & 2.307 & 0.904 \\
\hline Sinjar & 408 & 0.080 & 7.273 & 0.134 & $11.36(1976)^{*}$ & $0.034^{*}$ & 2.148 & 0.734 \\
\hline Dokan & $490(1974)^{*}$ & $0.007^{*}$ & 9.660 & 0.074 & $12.72(1976)^{*}$ & $0.006^{*}$ & 2.152 & 0.728 \\
\hline Derbandghan & 220 & 0.118 & 6.997 & 0.171 & $9.276(1984)^{*}$ & $0.033^{*}$ & 10 & 0.088 \\
\hline
\end{tabular}

Note: * refers to the inhomogeneous stations at the $5 \%$ significance level.

The spring precipitation series for all stations except for Dokan were considered as useful. Dokan station was considered as doubtful in the spring precipitation data. The break point years for the spring precipitation series of Sinjar, Dokan, and Darbandikhan stations were found in 1976, 1976, and 1984, respectively.

According to the results of homogeneity for the seasonal precipitation series, the greatest number of the inhomogeneities were obtained by the VNR test in the winter, whereas this test did not detect any inhomogeneous precipitation series in the spring seasons. In addition, BR test detected more inhomogeneous data series in the spring season than winter season. Consequently, the results showed that these tests sometimes have inconsistencies. These inconsistencies also were detected by several researchers (Feng et al., 2004; Sahin and Cigizoglu, 2010). Talaee et al., (2014) expressed that these inconsistencies obtained from homogeneity tests in some situations may be connected to the different sensitivities of the methods to break in the data sets. 
It is not easy to detect trends of precipitation time series when there is a high variability of rainfall (i.e. the breaks in time series for rainfall). In the literature, Talaee et al. (2014) emphasized that there is a consistency between the results of the homogeneity tests and the ability of trend revelation in rainfall. Consequently, we can said that the results of the homogeneity test may be related to the validity of trend detection in the time series. Therefore, the non-homogeneous data should be corrected before their use in the trend analysis.

The homogenous data belonging to the stations that are identified as inhomogeneous according to the SNH, Pettitt, VNR, and BR tests can be obtained from double mass curve analysis. In this analysis, total annual and seasonal precipitation data belonging to the inhomogeneous stations were fixed with the homogeneous neighboring stations, where minimum four neighboring stations were selected for this study. 4, 4, and 3 synoptic stations were identified as inhomogeneous annual, winter, and spring precipitation data according to four tests, respectively. Mosul, Arbil and Derbandghan stations' precipitation data were fixed and tried to make them homogenous. After the correction, the homogeneity of the annual and seasonal precipitation data was re-tested. Table 4 showed the results of homogeneity tests for the stations' annual precipitation data after the correction.

Table 4. The test results for the annual precipitation series after the correction.

\begin{tabular}{|c|c|c|c|c|c|c|r|r|}
\hline \multirow{2}{*}{ STATIONS } & \multicolumn{2}{|c|}{ Pettitt's test } & \multicolumn{2}{c|}{ SNHT } & \multicolumn{2}{c|}{ BR test } & \multicolumn{2}{c|}{ VNR test } \\
\cline { 2 - 9 } & $\mathrm{KN}$ & P-value & To & P-value & $\mathrm{Q}$ & P-value & $\mathrm{N}$ & P-value \\
\hline Mosul & 362 & 0.224 & 6.977 & 0.125 & 7.600 & 0.347 & 1.935 & 0.391 \\
\hline Arbil & 272 & 0.450 & 4.920 & 0.327 & 6.892 & 0.420 & 1.625 & 0.056 \\
\hline Derbandghan & 166 & 0.380 & 2.673 & 0.740 & 5.617 & 0.440 & 1.918 & 0.391 \\
\hline
\end{tabular}

Darbandikhan and Dokan station were taken as an example for the annual and seasonal data, respectively. As shown in Figure (3), inhomogeneity in the Darbandikhan and Dokan station's precipitation data were eliminated, and the new data successfully passed from the four mentioned homogeneity tests.
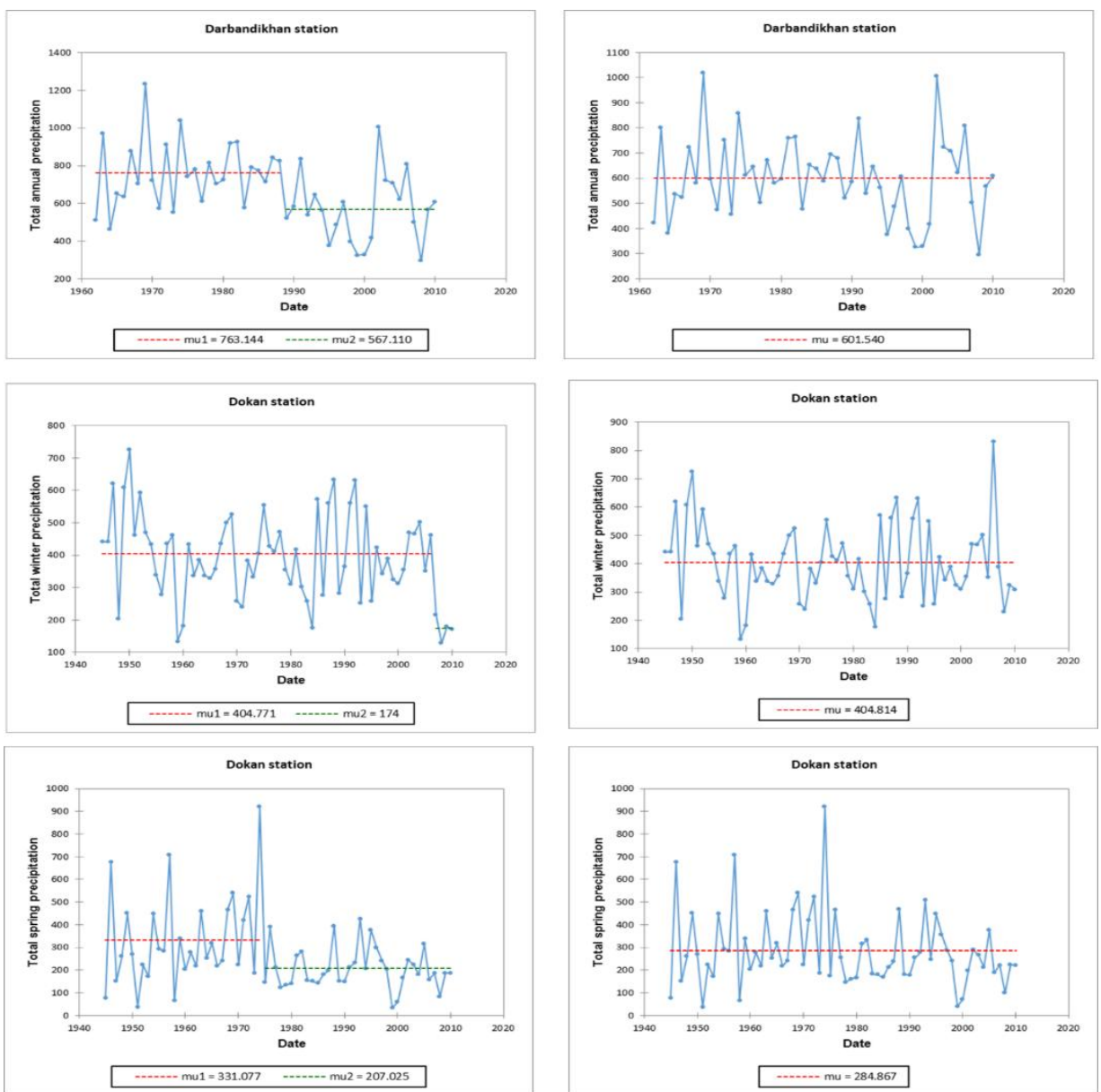

Fig 3. Testing of annual and seasonal homogeneity by four homogeneity tests, before and after the correction for two stations. 


\section{Conclusions}

This study aims to check of the homogeneity of annual and seasonal precipitation data. For this purpose, four homogeneity tests were applied to the observed climate data from nine stations located in Iraq for long-term years. The inhomogeneous precipitation time series and their break years were identified at a significance level of 0.05 . According to the results of the Pettitt (SNH) test, annual precipitation data series belonging to 2 (4) out of 9 stations were found to be inhomogeneous, whereas BR (VNR) tests showed that the annual precipitation data series were homogeneous for all except one station. According to the results of the SNHT and Pettitt test, 2 out of 9 stations showed inhomogeneity in the winter precipitation data, whereas BR and VNR tests detected 1 and 3 out of 9 stations as inhomogeneous in the seasonal data, respectively. Moreover, the high number of the inhomogeneity were obtained from the VNR and BR test in the winter and spring precipitation series, respectively. In general, it can be concluded that the SNHT, VNR, and BR tests are more sensitive for detecting the inhomogeneity for the annual, winter, and spring precipitation series on comparing with the other tests.

In the final phase of the study, data belonging to the stations that are identified as doubtful or suspect were tried to make homogeneous by using double mass curve analysis. After correction, the results showed that the new data have successfully passed the four mentioned homogeneity tests.

Finally, we hope that the results of the present study would be a reference for future to researchers who studied on the water resources, hydrological processes, and climate change fields in Iraq.

\section{References}

[1]. Alexanderson HA 1986. A homogeneity test applied to precipitation data. J. Climatol. 6: 661-675.

[2]. AL-Lami, A. M., AL-Timimi, Y. K., \& AL-Salihi, A. M. 2014. The Homogeneity Analysis of Rainfall Time Series for Selected Meteorological Stations in Iraq.Iraqi Academic Scientific Journals 10(2): 60-77.

[3]. Buishand TA 1981. The analysis of homogeneity of long-term rainfall records in the Netherlands. KNMI Scientific Report WR 817, De Bilt, The Netherlands.

[4]. Buishand TA 1982. Some methods for testing the homogeneity of rainfall records. J Hydrol 58:11-27.

[5]. Schonwiese CD., \& Rapp J., 1997. Climate Trend Atlas of Europe Based on Observations 1891-1990. Kluwer Academic Publishers: Dordrecht, The Netherlands.

[6]. Feng S, Hu Q, \&Qian W., 2004. Quality control of daily meteorological data in China, 1951-2000: A new dataset. Int J Climatol 24:853-870.

[7]. Wijngaard J.B., Kleink Tank AMG., Konnen GP., 2003. Homogeneity of $20^{\text {th }}$ Century European Daily Temperature and Precipitation Series. Int. J. Climatol, 23, 679-692.

[8]. Kahya E., Arıkan, B. B., \& Duran, E. A., 2016. Homogeneity Analysis of Precipitation Series in Turkey. Conference of International Congress on Advances in Civil Engineering, September 21-23.

[9]. Kang HM. \& Yusof F., 2012. Homogeneity Tests on Daily Rainfall Series in Peninsular Malaysia. , Int. J. Contemp. Math. Sciences, 7 (1): $9-22$.

[10]. Karabork MC., Kahya E. \& Komuscu AU., 2007. Analysis of Turkish Precipitation Data: Homogeneity and the Southern Oscillation Forcings on Frequency Distributions. Hydrological Processes, John Wiley \& Sons, Ltd., 21, PP. 3203-3210.

[11]. Mahmood Agha OM., \& Şarlak N., 2016. Spatial and temporal patterns of climate variables in Iraq. Arabian Journal of Geosciences, 9(4): 1-11.

[12]. Pettitt AN., 1979. A non-parametric approach to the change-point detection. Appl. Statist. 28(2): 126-135.

[13]. Sahin S., \& Cigizoglu HK., 2010. Homogeneity analysis of Turkish meteorological data set. Hydrol. Process, 24(8): 981-992.

[14]. Tabari H., Shifteh Somee B., \& Rezaeian Zadeh M., 2011. Testing for long term trends in climatic variables in Iran. Atmos. Res., 100(1): 132-140.

[15]. Talaee PH., Kouchakzadeh M., \& Some'e, BS., 2014. Homogeneity analysis of precipitation series in Iran. Theoretical and Applied Climatology, 118(1-2): 297- 305.

[16]. Peterson TC., Vose R., Schmoyer R., Razuvaev V., 1998. Global Historical Climatology Network (GHCN) Quality control of monthly temperature data. International Journal of Climatology, 18 (11): 1169-1179.

[17]. Tuomenvirta H., Alexandersson H., Drebs A., Frich P., \& Nordli PO., 2000. Trends in Nordic and Arctic temperature extremes and ranges. J. Climate 13(5): 977-990

[18]. Von Neumann J., 1941. Distribution of the ratio of the mean square successive difference to the variance. Ann Math Stat., 13: 367395.

[19]. Yildırım YE., Türkes M., \& Tekiner M., 2004. Time-series analysis of long-term variations in streamflow data of some stream-flow stations over the Gediz basin and in precipitation of the Akhisar station. Pakistan J. Biol. Sci. 7(1): 17-24. 